\title{
Review Article \\ The wastewater resistome: \\ Lurking antibiotic resistance in the environment
}

\author{
Dev Raj Joshi ${ }^{1^{*}}$ \\ ${ }^{1}$ Central Department of Microbiology, Tribhuvan University, Kirtipur, Kathmandu, Nepal
}

*Corresponding author: Dr. Dev Raj Joshi; Central Department of Microbiology, Tribhuvan University, Kirtipur, Kathmandu, Nepal Email: dev.joshi@microbiotu.edu.np

\begin{abstract}
Antibiotic resistant bacteria and their resistance determinants have been frequently reported in all types of environments especially in water systems. The collection of antibiotic resistant genes and precursors in host bacteria occupying wastewater environment represents wastewater resistome. This resistome is highly potential to resist almost all types of antibiotics exposed to the environment. Since antimicrobial resistance could be transferred from environmental bacteria to clinical or veterinary pathogens and vice versa, wastewaters systems are spawning grounds for global antibiotic resistance, with potentially serious infection consequences for human and animals. Although the sub-lethal dose of antibiotics is key stimulating factor, however, physiological and environmental stress on bacteria due to various factors including non-antibiotic antimicrobials, organic pollutants like PAHs, chlorinated phenols and heavy metals may also drivethe enrichment of antibiotic resistance genes in the environment. Although actual key mechanisms for survival of antibiotic resistance bacteria, proliferation and dissemination of such genes in wastewater are still elusive, this mini review briefly describes environmental resistome, possible drivers and dissemination paths of resistance genes in wastewater systems. Considering the hazards, efficient wastewater treatment technologies are needed to be developed for mitigation of antibiotic resistance bacteria and resistance genes.
\end{abstract}

Key words: environmental resistome, wastewater, antibiotic resistant genes, mobile genetic elements

\section{INTRODUCTION}

Emergence of microbial resistance to almost all types of antibiotics has posed a serious threat to human and animal health increasing perilous risk towards microbial infections worldwide (Berendonk et al. 2015). More recently, the environment is increasingly being recognized for itsimportant role in the global spread of clinically relevant antibiotic resistance (Singer et al. 2016) because environmental microorganisms are highly antibiotic resistant and harbor responsible genetic content. Although antibiotic resistant bacteria (ARB) and genes (ARGs) are found in different environments (Allen et al. 2010; Wright et al. 2010), wastewater treatment plants (WWTPs) for example those treating sewage and municipal (Rizzo et al. 2013; Mao et al. 2015; Rodriguez-Mozaz et al. 2015), hospital (Rodriguez-Mozaz et al. 2015), pharmaceutical (Tao et al. 2016; Wang et al. 2015), swine farm (Zhu et al. 2013), livestock farm (Chen et al. 2015), tannery wastewater (Wang et al. 2013) have been reported as important reservoirs of ARGs. Since these wastewaters are normally contaminated with high or sub-lethal concentrations of antibiotics (Watkinson et al. 2007) which create a selective pressure for acquiring the resistance via horizontal spread of ARGs.Additionally, water environments are favorable for transfer of resistance genes (Aydin et al. 2016). Therefore, such WWTPs are often considered as hot spot for resistant bacteria and genes (Rizzo et al. 2013) and could be a point source to disseminate into natural environment like fresh water sediments (Czekalski et al. 2014) and other environments. These reports clearly indicate that antibiotic resistance is lurking in the wastewaters and wastewater treatment plants. It is, therefore interesting to understand increasing extent of resistome, potential drivers and their dissemination through wastewater treatment systems.

\section{Environmental resistome}

The term 'resistome'was proposed by Wright (2007) to describe the totality of all the antibiotic resistance genes and their precursors in both pathogenic and nonpathogenic bacteria. WWTPs accumulatecommunities of enteric- and environmental bacteria coupled with 
residual concentrations of antibiotics, disinfectants, and heavy metals, which potentially select for ARB (Marano and Cytryn 2017) and spread antibiotic resistance.The wastewater antibiotic resistome is dynamic and ever expanding with varieties of antibiotic resistant genes and mobile genetic elements (Wang et al. 2013; Chen et al. 2015; Li et al. 2015; Mao et al. 2015; Munck et al. 2015; Rodriguez-Mozaz et al. 2015; Tao et al. 2016; Yang et al. 2016; Guo et al. 2017; Su et al. 2017) that reveal lurking nature of antibiotic resistance.

Szczepanowski et al. (2009) found 140 and 123 different resistance-gene-specific amplicons including aminoglycoside, beta-lactam, chloramphenicol, fluoroquinolone, macrolide, rifampicin, tetracycline, trimethoprim and sulfonamide resistance genes as well as multidrug efflux and small multidrug resistance genes on total plasmid DNA preparations obtained from bacteria of activated sludge or the WWTP's final effluents. Recently, the rapid progress in high throughput sequencing and functional gene array has allowed comprehensive profiling of ARGs in environmental samples with the metagenomics approach (Tao et al. 2016; Guo et al. 2017). A metagenomic profiling of ARGs and MGEs in tannery WWTP revealed that aerobic and anaerobic sludge contained sul1 and tet genes in high abundance accompanied with over 70 types of insertion sequences and class 1 integrase (Wang et al. 2013). Su et al. (2017) detected twenty resistance gene types consisting of 381 subtypes with the three most dominant resistance gene types, conferring aminoglycoside, tetracycline, and beta-lactam resistance in sewage.Another recent metagenomic analysis reported the occurrence of 42 and 51 different subtypes of ARGsin the activated sludge and digested sludge, respectively along with abundant MGEs including plasmids, transposons, integrons (intI1) and insertion sequences (ISSsp4, ISMsa21, ISMba16) (Guo et al. 2017). High priority carbapenem-resistant gene $\left(b l a_{\mathrm{KPC}-2}\right)$ and its hosts including Klebsiella spp., Enterococcus spp., Acinetobacter spp., Escherichia spp., Shigella spp. were also detected in all stages of WWTP (Yang et al. 2016).

\section{Environmental drivers of antibiotic resistance}

Horizontal gene transfer is a key mechanism for evolution of bacterial genomes and can disseminate the genes among microbial communities in environmental reservoirs and potential pathogens (Figure 1). It is well understood that selective pressure created by low concentration of antibiotics can promote horizontal gene transfer in environment. However, the mechanisms of antibiotic resistance may not necessarily evolve only in response to antibiotics (Piddock et al. 2006) and surprisingly, the presence of antibiotics did not significantly increase the efficiency of conjugation in many bacteria (Lopatkin et al. 2016). Instead, physiological status of microbial cell and the environmental stress over the cell could be important determinant of antimicrobial resistance (Figure 1). Bacterial stress responses due to exposure to nutrient starvation/limitation, reactive oxygen and nitrogen species, membrane damage, elevated temperature, and ribosome disruptionin wastewater treatment systems may initiate microbial response that could positively recruit the resistance determinants in microbial community enhancing their antimicrobial resistance (Poole 2012). These findings indicate that horizontal transfer of ARGs in environmental bacteria might also be enhanced due to several factors besides antibiotics. As mentioned, consistent stress on microbial cells may play important role to encourage acquiring resistance. Several toxic substances including heavy metals (Li et al. 2015; ), chlorinated phenols (BakerAustin et al. 2006; Muller et al. 2015), triclosan biocides (Karatzas et al. 2007), disinfectants (Zhang et al. 2017), herbicides (Kurenbach et al. 2015), different polyaromatic hydrocarbons_(Chen et al. 2017), including pyrene (Sun et al. 2015) have been reported to co-select or enrich the ARGs mostly encoding multidrug resistant efflux pumps in the water or soil environment.Since biocide/metal resistance genes (BMRGs) for example, mercury resistance genes and the qacE $\Delta 1$ gene (resistance to quaternary ammonium compounds) generally cooccur with ARGs on plasmids, and cadmium/zinc and macrolide/aminoglycoside resistance genes are linked (Pal et al. 2015). Besides, efflux pumps can often provide cross-resistance to multiple chemicals.

In addition, mobile genetic elements (MGEs) including plasmids, insertion sequences and transposons play important role in resistance gene transfer (Frost et al. 2005; Li et al. 2015). So higher abundance of the MGEs enhances the risk of disseminating the antibiotic resistance in environment.

\section{Antibiotic resistance dissemination paths}

Application of antibiotics for medicine and veterinary use provides selective pressure to acquire resistance among selected bacteria in gut microbiome communities in humans and animals (Figure 2). The 


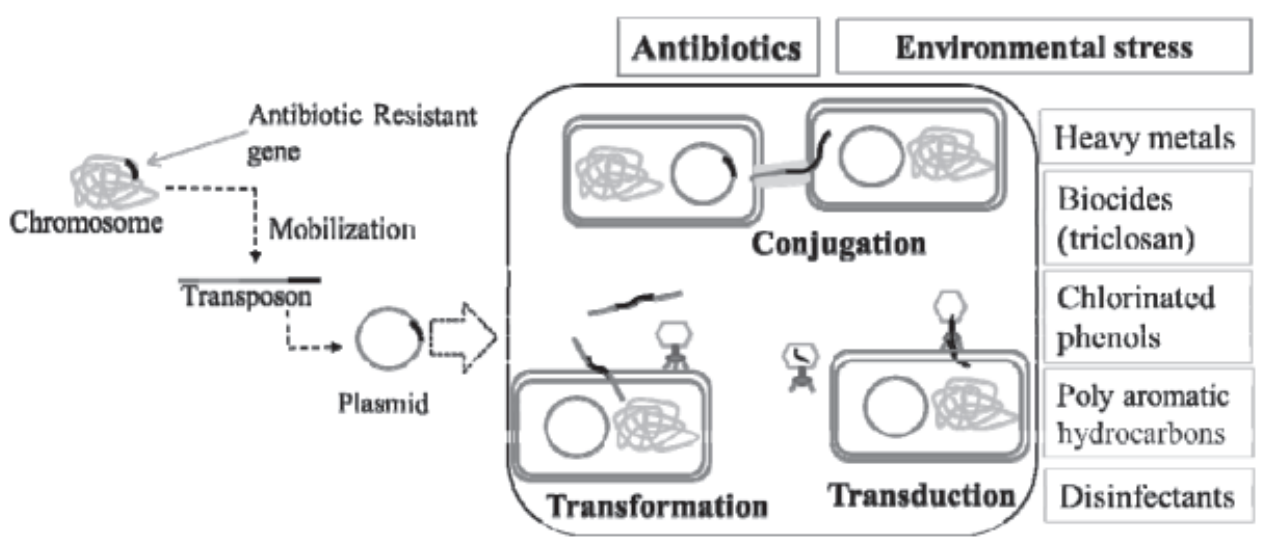

Figure 1: Antibiotic resistant gene mobilization, horizontal gene transfer and potential drivers for proliferation of antibiotic resistance in wastewater.

resistant bacteria are transferred to environment for example wastewater by various means. Once entered to the wastewater systems, ARB can disseminate their resistance carriage among other members of the endogenous microbial community. Additionally huge amount of the persistent antibiotics trigger spread of antibiotic resistanceas the hot spot in WWTPs (Singer et al. 2016). Unfortunately, WWTPs do not efficiently remove all ARGs that are subsequently released in treated effluents (Yang et al. 2014). The treated water if reclaimed for human use, the resistance genes and their host would be exposed to humans; and at same time if discharged, the effluent contaminates receiving water bodies, soil and groundwater aquifer that ultimately may transport antibiotic resistance determinants again to humans (Figure 2).

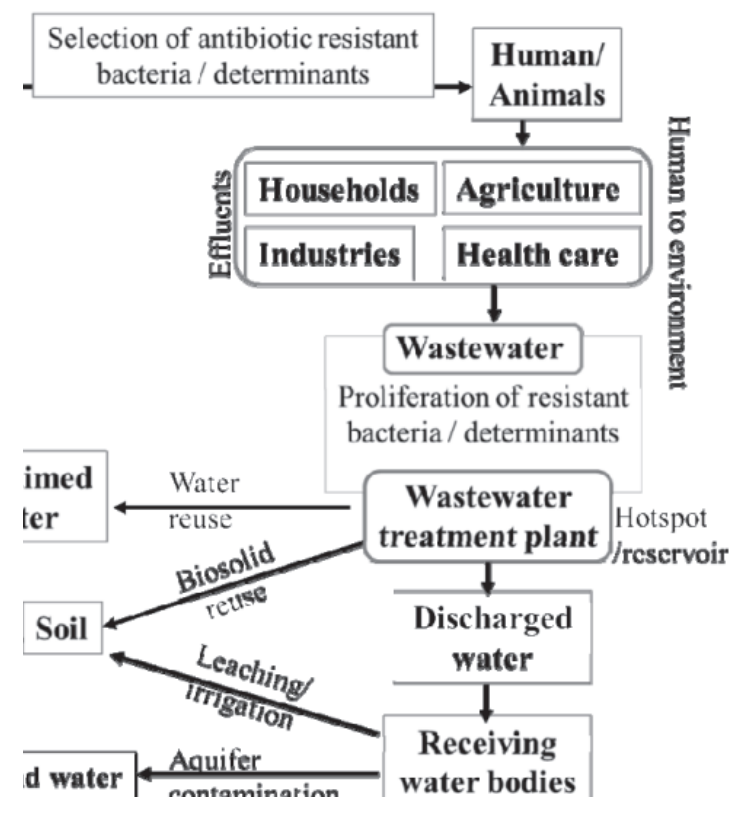

Figure 2: Potential dissemination of antibiotic resistance bacteria and their genes (modified from Guo et al. 2017)

The use of biosolids or sludge as a manureis also a potential route of human exposure to antibiotic resistance genes through consumption of contaminated crops (Rahube et al. 2016). Thus WWTPs lead to multi-lateral dissemination of antibiotic resistance in environment channeling back to humans.

In fact, this environmental resistome constituting large amount of resistant genes have the high potential to be transferred to pathogens and the evidences that at least 
some clinically relevant resistance genes have originated in environmental microbes have been reported (Wright 2010). However, core resistome is unique to the WWTP environment, with $10 \%$ of the resistance genes found outside the WWTP environment (Munck et al. 2015) indicating low frequency of genetic exchange between wastewater and human resistome. Even in the case, the potential risk of acquiring antibiotic resistance to pathogens remains high enough to challenge the efficiency of commonly used antibiotics.

\section{CONCLUSION}

Water and wastewater systems are major part of environmental resistome as a great reservoir of antibiotic determinants and their host bacteria. It is now seriously realized that emergence and dissemination of the antibiotic resistant bacteria and their respective genes and mobile elements in the environment could pose much higher risk to human health than previously expected. Therefore the global antibiotic resistance control strategies should consider to recommend stringent criteria for discharge of antibiotics in wastewater. Although some factors for induction and spread of resistant determinants have been reported but the core mechanism and driving forces acting on environmental resistome are still elusive. Research efforts should focus to unravel the key factors, mechanisms and transmission paths of environmental resistome. Engineered biological systems to treat water and wastewater are reliable solutions to mitigate pollutants. Innovative treatment technologies should be developed and adopted to minimize the contents of the environmental resistome which would be great contribution in tackling the global burden of antibiotic resistance.

\section{REFERENCES}

Allen HK, Donato J, Wang HH, Cloud-Hansen KA, Davies JE and Handelsman J (2010) Call of the wild: antibiotic resistance genes in natural environments. Nat Rev Microbiol 8: 251-259.

Aydin S, Ince B and Ince O (2016) Assessment of anaerobic bacterial diversity and its effects on anaerobic system stability and the occurrence of antibiotic resistance genes. BioresourTechnol 207: 332-338.

Baker-Austin C, Wright MS, Stepanauskas R and McArthur JV (2006) Co-selection of antibiotic and metal resistance. Trends Microbiol 14 (4): 176-182.
Berendonk TU, Manaia CM, Merlin C, Fatta-Kassinos D, Cytryn E, Walsh F, Burgmann H, Sorum H, Norstrom M, Pons MN, Kreuzinger N, Huovinen P, Stefani S, Schwartz T, Kisand V, Baquero F and Martinez JL (2015) Tackling antibiotic resistance: the environmental framework. Nat Rev Microbiol 13 (5): 310-317.

Chen B, Hao L, Guo X, Wang N and Ye B (2015) Prevalence of antibiotic resistance genes of wastewater and surface water in livestock farms of Jiangsu Province, China. Environ Sci Pollut Res Int 22(18): 3950-3959.

Chen B, He R, Yuan K, Chen E, Lin L, Chen X, Sha S, Zhong J, Lin L, Yang L, Yang Y, Wang X, Zou S and Luan T (2017) Polycyclic aromatic hydrocarbons (PAHs) enriching antibiotic resistance genes (ARGs) in the soils. Environ Pollut 220(Part B): 1005-1013.

Czekalski N, Diez EG and Burgmann H (2014) Wastewater as a point source of antibioticresistance genes in the sediment of a freshwater lake. ISME J 8: 1381-1390.

Frost LS, Leplae R, Summers AO and Toussaint A (2005) Mobile genetic elements: the agents of open source evolution. Nat Rev Microbiol 3(9): 722-732.

GuoJ, Li J, Chen H, Bond PL and YuanZ (2017) Metagenomic analysis reveals wastewater treatment plants as hotspots of antibiotic resistance genes and mobile genetic elements. Water Res 123: 468-478.

Karatzas KA, Webber MA, Jorgensen F, Woodward MJ, Piddock LJ and Humphrey TJ (2007) Prolonged treatment of Salmonella enterica serovar Typhimurium with commercial disinfectants selects for multiple antibiotic resistance, increased efflux and reduced invasiveness. I Antimicrob Chemother 60(5): 947-955.

Kurenbach B, Marjoshi D, Amabile-Cuevas CF, Ferguson GC, Godsoe W, Gibson P and Heinemann JA (2015) Sublethal exposure to commercial formulations of the herbicides dicamba, 2, 4-dichlorophenoxyacetic acid, and glyphosate cause changes in antibiotic susceptibility in Escherichia coli and Salmonella enterica serovar Typhimurium. m Bio 6(2): e0000915. 
Li AD, Li LG and Zhang T (2015) Exploring antibiotic resistance genes and metal resistance genes in plasmid metagenomes from wastewater treatment plants. Front Microbiol 6: 1025, 1-11.

Lopatkin AJ, Huang S, Smith RP, Srimani JK, Sysoeva TA, Bewick S, Karig DK and You L (2016) Antibiotics as a selective driver for conjugation dynamics. Nat Microbiol 14(6): 16044.

Mao D, Yu S, Rysz M, Luo Y, Yang F, Li F, Hou J, $\mathrm{Mu} \mathrm{Q}$ and Alvarez PJ (2015) Prevalence and proliferation of antibiotic resistance genes in two municipal wastewater treatment plants. Water Res 85: 458-466.

Marano RBM and Cytryn E (2017) The mobile resistome in wastewater treatment facilities and downstream environments. Antimicrobial resistance in wastewater treatment processes (Keen P L \& Fugere R, eds.) John Wiley \& Sons Inc pp. 129-155.

Muller JF, Ghosh S, Ikuma K, Stevens AM and Love NG (2015) Chlorinated phenol-induced physiological antibiotic resistance in Pseudomonas aeruginosa. FEMS Microbiol Lett 362(21): fnv 172.

Munck C, Albertsen M, Telke A, Ellabaan M, Nielsen PH and Sommer MO (2015) Limited dissemination of the wastewater treatment plant core resistome. Nat Commun 6: 8452.

Pal C, Bengtsson-Palme J, Kristiansson E and Joakim Larsson DGJ (2015) Co-occurrence of resistance genes to antibiotics, biocides and metals reveals novel insights into their co-selection potential. BMC Genomics 16: 964-978.

Piddock LJV (2006) Clinically relevant chromosomally encoded multidrug resistance efflux pumps in bacteria. Clin Microbiol Rev 19: 382-402.

Poole K(2012) Bacterial stress responses as determinants of antimicrobial resistance. J Antimicrob Chemother 67(9): 2069-2089.

Rahube TO, Marti R, Scott A, Tien Y-C, Murray R, Sabourin L, Duenk P, Lapen DR and Topp E (2016) Persistence of antibiotic resistance and plasmidassociated genes in soil following application of sewage sludge and abundance on vegetables at harvest. Can J Microbiol 62: 600-607.

Rizzo L, Manaia C, Merlin C, Schwartz T, Dagot C,
Ploy MC, Michael I and Fatta-Kassinos D (2013) Urban wastewater treatment plants as hotspots for antibiotic resistant bacteria and genes spread into the environment: a review. Sci Total Environ 447: 345-360.

Rodriguez-Mozaz S, Chamorro S, Marti E, Huerta B, Gros M, Sanchez-Melsio A, Borrego CM, Barcelo D and Balcazar JL (2015) Occurrence of antibiotics and antibiotic resistance genes in hospital and urban wastewaters and their impact on the receiving river. Water Res 69: 234-242.

Singer AC, Shaw H, Rhodes V and Hart A (2016) Review of antimicrobial resistance in the environment and its relevance to environmental regulators. Front Microbiol 7: 1728, 1-22.

Su J-Q, An X-L, Li B, Chen Q-L, Gillings MR, Chen H, Zhang T and Zhu Y-G (2017) Metagenomics of urban sewage identifies an extensively shared antibiotic resistome in China. Microbiome 5: 84.

Sun M, Ye M, Wu J, Feng Y, Shen F, Tian D, Liu K, Hu F, Li H, Jiang X, Yang L and Kengara FO (2015) Impact of bioaccessible pyrene on the abundance of antibiotic resistance genes during Sphingobium sp.- and sophorolipid-enhanced bioremediation in soil. J Hazard Mater 300: 121-128.

Szczepanowski R, Linke B, Krahn I, Gartemann KH, Gutzkow T, Eichler W, Puhler A and Schluter A (2009) Detection of 140 clinically relevant antibiotic resistance genes in the plasmid metagenome of wastewater treatment plant bacteria showing reduced susceptibility to selected antibiotics. Microbiology 155: 2306-2319.

Tao W, Zhang XX, Zhao F, Huang K, Ma H, Wang Z, Ye L and Ren H (2016) High levels of antibiotic resistance genes and their correlations with bacterial community and mobile genetic elements in pharmaceutical wastewater treatment bioreactors. PLoS ONE 11(6): e0156854.

Wang J, Mao D, Mu Q and Luo Y (2015) Fate and proliferation of typical antibiotic resistance genes in five full-scale pharmaceutical wastewater treatment plants. Sci Total Environ 526: 366-373.

Wang Z, Zhang X, Huang K, Miao Y, Shi P, Liu B, Long C and Li A (2013) Metagenomic profiling of antibiotic resistance genes and mobile genetic 
elements in a tannery wastewater treatment plant. PLoS ONE 8(10): e76079.

Watkinson AJ, Murby EJ and Costanzo SD (2007) Removal of antibiotics in conventional and advanced wastewater treatment: Implications for environmental discharge and wastewater recycling. Water Res 41(18): 4164-4176.

Wright GD (2007) The antibiotic resistome: the nexus of chemical and genetic diversity. Nat Rev Microbiol 5(3): 175-186.

Wright GD (2010) Antibiotic resistance in the environment: a link to the clinic? Curr Opin Microbiol 13: 589-594.

Yang F, Mao D, Zhou H, Luo Y (2016) Prevalence and fate of Carbapenemase genes in a wastewater treatment plant in Northern China. PLoS ONE 11 (5): e0156383.

Yang Y, Li B, Zou S, Fang HHP and Zhang T (2014) Fate of antibiotic resistance genes in sewage treatment plant revealed by metagenomics approach. Water Res 62: 97-106.

Zhang Y, Gu AZ, He M, Li D and Chen J (2017) Subinhibitory concentrations of disinfectants promote the horizontal transfer of multidrug resistance genes within and across genera. Environ Sci Technol 51 (1): 570-580.

Zhu YG, Johnson TA, Su JQ, Qiao M, Guo GX, Stedtfeld RD, Hashsham SA and Tiedje JM (2013) Diverse and abundant antibiotic resistance genes in Chinese swine farms. Proc Natl Acad Sci USA 110 (9): 3435-3440. 